\title{
Microtensile bond strength of quartz fiber posts to different composite cores
}

\section{Zahra Khamverdi(a) \\ Shahin Kasraei(a) \\ Mohadese Azarsina ${ }^{(b)}$ \\ Faeze Gheysari(b)}

(a) Dental Research Center, Dental School, Hamadan University of Medical Sciences, Hamadan, Iran.

(b) Department of Operative Dentistry, Dental School, Hamadan University of Medical Sciences, Hamadan, Iran.
Declaration of Interests: The authors certify that they have no commercial or associative interest that represents a conflict of interest in connection with the manuscript.

Corresponding author:

Mohadese Azarsina

Email: azarsina2003@yahoo.com

Received for publication on Jan 09, 2011 Accepted for publication on May 24, 2011

\begin{abstract}
The aim of this in vitro study was to assess the microtensile bond strength of quartz fiber posts to different composites, and to composite combinations used as core materials. Thirty fiber posts were treated with a $24 \%$ hydrogen peroxide solution and silanized. The posts were divided into 5 groups according to the resin composite used as follows ( $\mathrm{n}=6$ ): G1 - Ælite Flow (Bisco, Inc), G2 - Filtek Z250 (3M ESPE), G3 - Biscore (Bisco, Inc), G4 - Ælite Flow + Filtek Z250, G5 - Ælite Flow + Biscore. The resin composites were placed around the posts to produce cylindrical specimens. Two $1-\mathrm{mm}^{2}$ thick sticks containing the post in the center and composite cores on both ends were provided from each cylinder and tested for microtensile strength with a crosshead speed of $0.5 \mathrm{~mm} / \mathrm{min}$. One-way ANOVA and Tukey HSD tests were used for statistical analysis. Fractured surfaces were observed using a stereomicroscope with $20 \times$ magnification. Scanning electron microscopy (SEM) was used to evaluate the interface of the fractured sticks. The results showed that G2 had the highest bond strength values, and the lowest values were seen with G3. There were significant differences between groups 1, 2, 4 and groups 3, $5(\mathrm{p}<0.05)$. Under the stereomicroscope, most of the failures were adhesive between the post and core material. Under SEM, Ælite and Z250 had smoother surfaces than Biscore, containing less porosities and voids.
\end{abstract}

Descriptors: Composite Resins; Dental Bonding; Post and Core Technique.

\section{Introduction}

Fiber-reinforced composite (FRC) posts, which were introduced in the early 1990s, are used as an alternative to metal posts to restore endodontically treated teeth with extensive loss of tooth coronal structure. ${ }^{1}$

Some advantages of fiber posts over metal posts are the improvement of aesthetics, bonding to dentin and resistance to corrosion. ${ }^{2}$

Additionally, luting procedures of FRC posts can be carried out without friction within the walls of the root canal, and have resulted in a lower incidence of vertical root fractures. Several in vitro studies have reported that FRC posts showed more uniform distribution of occlusal stresses in the root dentin, and thereby occurrence of fewer and more favorable root fractures, which could often be repaired..$^{1,3-6}$

It was shown that posts do not reinforce endodontically treated teeth roots, but play an important role in retaining a core when large portions 
or the entire clinical crown has been destroyed. ${ }^{7}$

Fiber posts, in combination with core build-up composites, are used for restoration of extensively destroyed teeth. The clinical success of post-core restorations depends on the composite used and the quality of the adhesion between the post and core, which is indeed the zone with which materials with different composition are in contact. The durability of a restoration with a composite core depends on the bond between the composite resin and the remaining tooth structure, and also on the bond between the composite core and the fiber post, which helps in stress distribution under functional loading. ${ }^{8}$

A variation of composite resin materials, including packable (high elastic modulus), micro hybrid (intermediary elastic modulus) and flowable (low elastic modulus) composites are available for core build-up of endodontically treated teeth. Some laboratory and technical evidence supports the use of flowable composites for restorations reinforced with FRC posts. SEM analyses have shown better integration and adaptation of flowable composite core materials on post surfaces than hybrid composites. In addition to the microscopic appearance of the contact surface of the composite core and fiber post, the bond strength between these two materials is important and must be taken into consideration. $^{9}$

The clinical use of flowable composites is questionable because of their inherent weakness and low elastic modulus, and also by the insufficient strength against occlusal loading, whereas hybrid composite resins have shown better clinical performance. ${ }^{10}$

Recently, flowable materials with high elastic modulus are being marketed, but adequate studies about them are still not available. ${ }^{11}$ It seems that performing simultaneously a method that uses the adaptation of flowable composites and better mechanical properties of composite core materials, can provide an acceptable clinical service for endodontically treated teeth. Therefore, the present study was designed to assess the microtensile bond strength of quartz fiber posts used in conjunction with different composites, and to composite combinations used as core materials.

\section{Methodology}

Thirty N-2 quartz fiber posts (DT Light-Post radiopaque, RTD, Grenoble, France) with a maximum external diameter of $1.8 \mathrm{~mm}$ were selected for this study. The posts were immersed in a $24 \%$ hydrogen peroxide solution for 10 minutes, and then rinsed with distilled water for 2 minutes and air-dried. A silane layer (Monobond S, Ivoclar-Vivadent, Schaan, Liechtenstein) was applied in the outer surface of all the posts, then they were left undisturbed for 60 seconds to dry completely. The treated posts were divided randomly into 5 groups for composite core build-up $(\mathrm{n}=6)$.

Core build-up was performed by the same procedure as described previously by Goracci et al. ${ }^{9}$ In the first group, each post was placed vertically on a glass slide in the center of a cylindrical polyglass matrix with $10-\mathrm{mm}$ diameter, and fixed with sticky wax. Then, the matrix was fixed to the slab using sticky wax. Flowable composite (Ælite Flow, Bisco, Inc., Schaumburg, USA) was placed in the mold in 1-mm thick increments. The thickness of each increment was measured with a probe, and was cured afterwards with a quartz-tungsten halogen lightcuring unit (Degulux, Degussa Dental, Hanau, Germany) for 30 seconds with an intensity of $450 \mathrm{~mW} /$ $\mathrm{cm}^{2}$. After the mold was filled with composite resin, it was separated from the glass slab and light cured from the side that was in contact with the slab for a further 30 seconds. The prepared samples were separated from the cylindrical molds.

In group 2, all the mentioned procedures for group 1 were done with a light-cured microhybrid composite resin (Filtek Z250, 3M ESPE, St. Paul, USA), and in group 3, with a packable dual-cured composite (Biscore, Bisco, Inc, Schaumburg, USA), in which the base and catalyst were mixed according to the manufacturer's instructions. In the other groups, after filling a $1.5 \mathrm{~mm}$ diameter mold with flowable composite and curing the composite, the mold was separated from the sample, and then this sample was placed in the center of a $10 \mathrm{~mm}$ diameter mold. The microhybrid resin composite in group 4 and the packable composite in group 5 were placed around the previously placed flowable composite to produce cylindrical specimens. After preparing all 
the samples, they were sectioned with a low speed diamond saw (IsoMet, Buehler LTD., Lake Bluff, USA). First, two sections parallel to the long axis of the post, and then sections perpendicular to the long axis of the post were prepared, resulting in sticks containing the post in the center and composite cores on both ends (Figure 1). The final sections diameters of $1 \pm 0.1 \mathrm{~mm}$ diameter, measured by a digital caliper (Mitutoyo CD15, Mitutoyo Co., Kawasaki, Japan).

Two sections from each sample were selected for microtensile bond strength tests, and a universal testing machine (EZ Test, Shimadzu Co., Kyoto, Japan) was used with a crosshead speed of $0.5 \mathrm{~mm} /$ min until failure occurred. Microtensile bond strength values were expressed in MPa by dividing the load at failure $(\mathrm{N})$ by the surface area $\left(\mathrm{mm}^{2}\right)$ of each specimen. Data were analyzed by the one-way ANOVA and Tukey HSD test. All tests were set at a 95\% level of confidence.

Fractured surfaces were observed using a stereomicroscope (Nikon Eclipse E600, Tokyo, Japan) with $20 \times$ magnification. Failures were scored as cohesive (failure within the post or the core material), adhesive (failure between post and the core material), or as mixed (mixture of both).

Two specimens from each group were used for SEM observation from both post and composite surfaces, to verify the morphology of these regions after the microtensile bond strength test. The specimens were cleaned ultrasonically for $5 \mathrm{~min}$ in deionized water (CP-104 EIA Intern., Paris, France), immersed in $95 \%$ ethanol, and gently air-dried. Each specimen was then gold sputter-coated (Polaron Range SC7620, Quarum Technology, Newhaven, UK), placed in a scanning electron microscope (JSM-5310, JEOL, Tokyo, Japan) and examined at $500 \times$ and $1000 \times$ magnifications.

\section{Results}

The means and standard deviations of the microtensile bond strength values are shown in Table 1 . Group 2 showed the highest bond strength values and the lowest ones were seen in group 3.

One-way ANOVA (Table 2) showed significant

Table 1 - Mean values of the microtensile bond strength of the studied groups.

\begin{tabular}{c|c|c}
\hline Groups & N & $\begin{array}{c}\text { Bond Strength (MPa) } \\
\text { (Mean } \pm \text { SD) }\end{array}$ \\
\hline 1 & 12 & $32.41 \pm 4.99^{\circ}$ \\
\hline 2 & 12 & $34.21 \pm 6.84^{\circ}$ \\
\hline 3 & 12 & $21.25 \pm 3.95^{\mathrm{b}}$ \\
\hline 4 & 12 & $29.35 \pm 5.48^{\circ}$ \\
\hline 5 & 12 & $21.55 \pm 4.37^{\mathrm{b}}$ \\
\hline
\end{tabular}

Superscripts indicate statistically significant differences between values a and $b$.
Table 2 - One-way ANOVA results.

Figure 1 - Schematic view of sample preparation in groups 4 and 5. P $=$ Post, $\mathrm{Fc}=$ Flowable composite, $\mathrm{C}=$ Composite

\begin{tabular}{c|c|c|c|c|c}
\hline & Sum of squares & df & Mean Square & $F$ & $P^{*}$ \\
\hline Between Groups & 1761.222 & 4 & 440.306 & 16.114 & .0001 \\
\hline Within Groups & 1502.822 & 55 & 27.324 & & \\
\hline Total & 3264.044 & 59 & & & \\
\hline
\end{tabular}

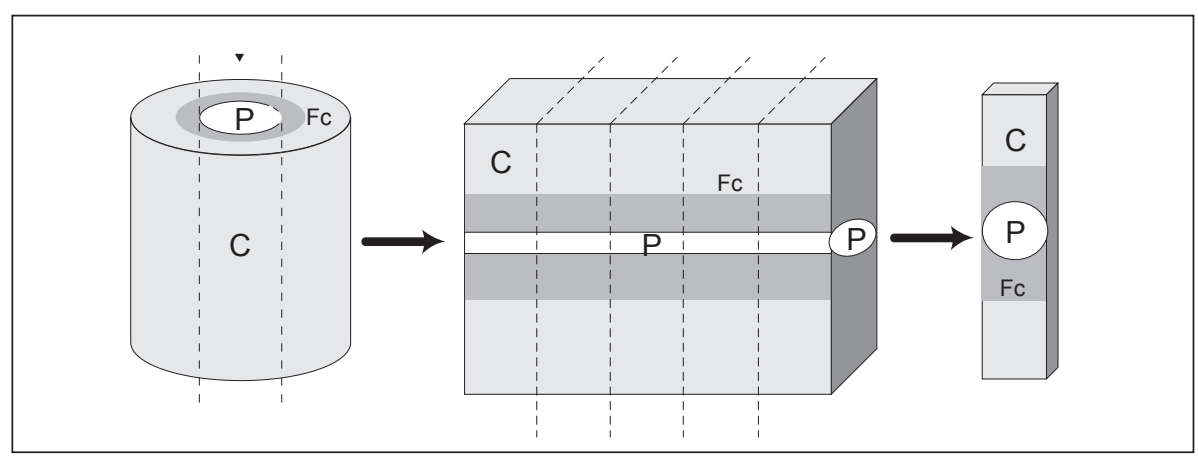


differences in bond strength among the groups $(\mathrm{p}<0.0001)$. The Tukey HSD test indicated significant differences between groups 1, 2, 4 and groups $3,5(\mathrm{p}<0.05)($ Table 1$)$.

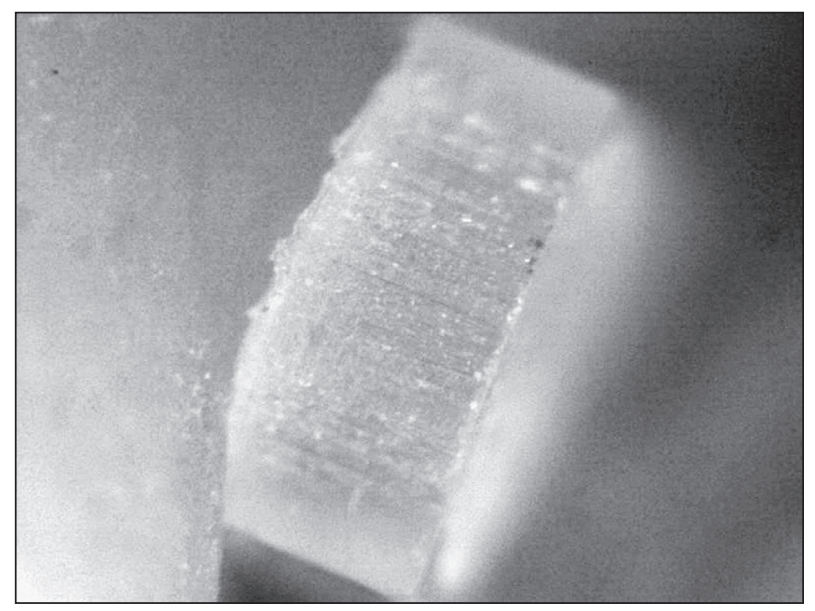

Figure 2 - Adhesive failure in stereomicroscopic view.
Stereomicroscopic assessment of the fractured surfaces revealed that most of the failures were the result of adhesive failures between the post and core material (Figure 2). Just one sample for groups 1, 2 and 3 showed mixed failure and one sample in group 5 showed cohesive failure at the interface of Ælite and Biscore composites.

SEM observations of the fractured surfaces showed that the Ælite and Z250 composites had smoother surfaces than the Biscore composite, containing less porosities and voids (Figure 3). The adaptation of the flowable and the microhybrid composite to the fiber post was better than that presented by the packable composite (Figure 4).

\section{Discussion}

For the restoration of endodontically treated teeth, there is currently a pronounced tendency to use materials such as fiber posts and composite res-
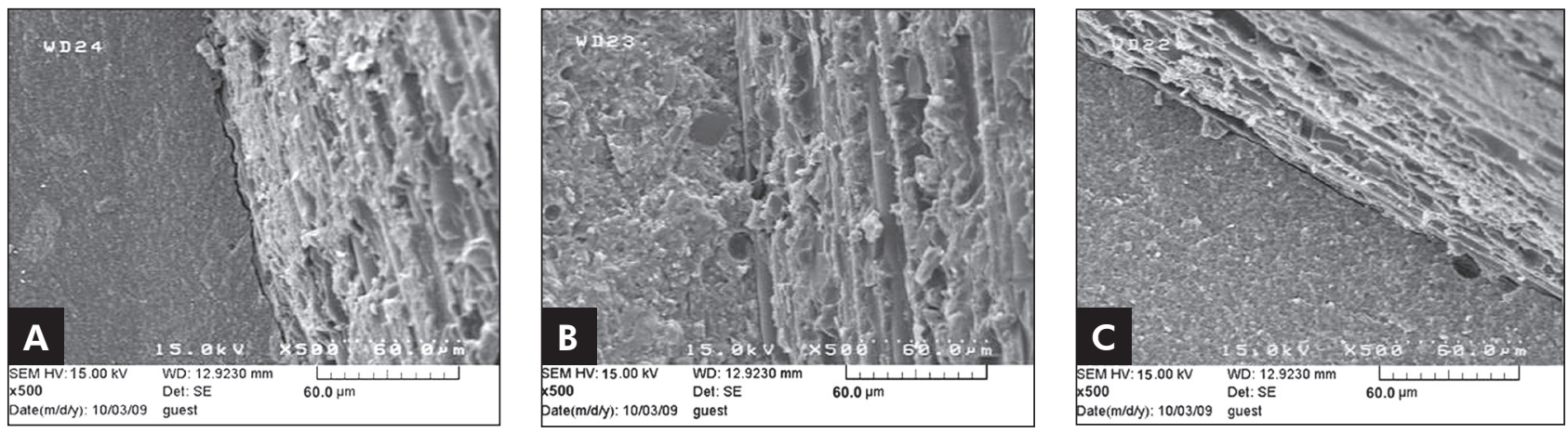

Figure 3 - SEM micrographs of the fractured surfaces showing mixed failures: Elite (A) and Z250 (C) had smoother surfaces than Biscore (B), containing less porosities and voids (The right side of each micrograph is the post and the left side is the composite resin).
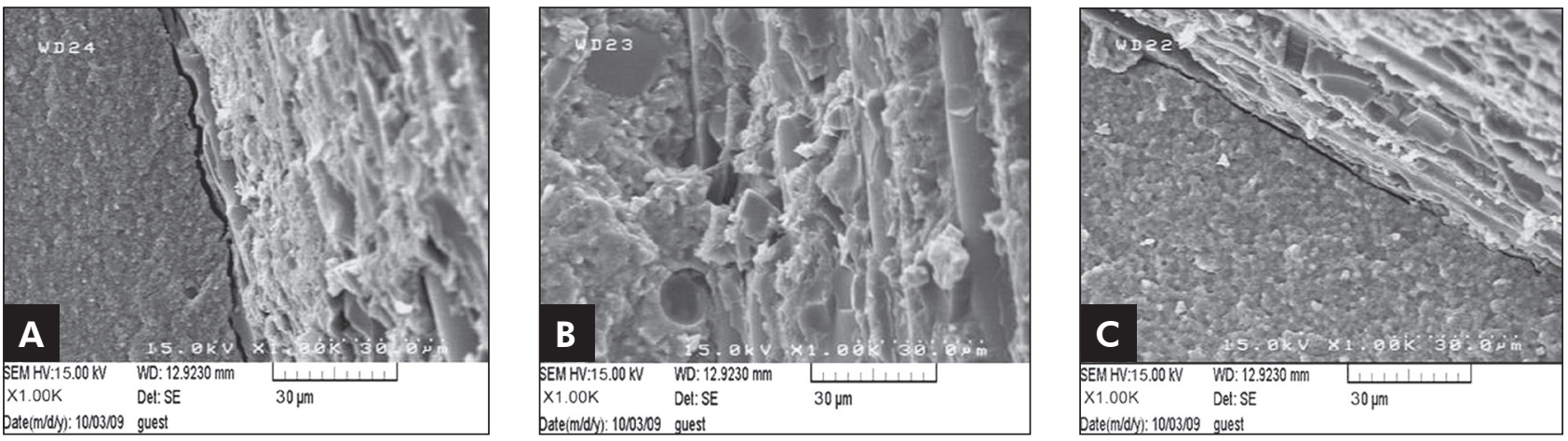

Figure 4 - SEM micrographs showing the better adaptation of Alite (A) and Z250 (C) to the post surface than Biscore (B) (The right side of each micrograph is the post and the left side is the composite resin). 
ins that have properties similar to tooth structure. ${ }^{10}$, 12-14

It is reported that hydrogen peroxide enhances the fiber post-composite core bond strength by removing the epoxy resin matrix that is found in the fiber posts, and by denuding intact fibers. Hydrogen peroxide $\left(\mathrm{H}_{2} \mathrm{O}_{2}\right)$ treatment is especially effective in enhancing bond strength of flowable composites to fiber posts because of the ability of these composites to penetrate into post surface irregularities..$^{15}$ MPS silane, which is used commonly in dentistry, cannot bond well to the epoxy resin matrix of fiber posts. Therefore removal of the epoxy resin by $\mathrm{H}_{2} \mathrm{O}_{2}$ results in the exposure of quartz fibers, enabling them to react with silane. Silanized quartz fibers bond chemically to methacrylate-based core materials, and this causes an increase in the post-core bond strength value. ${ }^{16}$

While it is assumed that the bond strength between the fiber post and core composite is the most important factor among these components, it is worth mentioning that one of the main problems with fiber posts is that the polymer matrix between fibers is too cross-linked and inactive, thereby leading to a weak adhesion between the post and the composite core material. ${ }^{17}$ Therefore, using a core material having maximum bond strength to the post is of great importance. The type of the composite core material also plays an important role in improving the performance of post/core-based restorations. ${ }^{16}$ This study was also designed to evaluate the microtensile bond strengths of quartz fiber posts binding to different composites (flowable, micro hybrid and packable), and to composite combinations used as core materials.

The microtensile bond strength test was performed according to previous studies that proved it as a standard test for bond strength testing in small surface areas. ${ }^{18,19}$

The results of the present study showed that the difference between the microhybrid and the flowable composite was not significant, and that the bond strength of the bond between the flowable composite and the post was satisfactory, which is in agreement with the findings of the previous study of Sadek et al. ${ }^{10}$
Use of flowable composites is recommended in some studies because of the ease of manipulation of the composite, and its good adaptation to the surrounding structures because of its low viscosity. ${ }^{20-22}$ In addition, its lower filler content has an advantage for dentists using it as a stress absorber, resulting in higher bond strength, although the lower filler content could lead to more polymerization shrinkage and consequently to more bond failures. ${ }^{21,23}$

The bond strength of the packable composite core was significantly lower than that of other composites, which is in accordance with the results of Salameh's study, ${ }^{7}$ but in contrast to the study of Sadek et al. who recommended packable composites as a good substitute for flowable and hybrid composites in these applications..$^{10}$ Packable composites are available at different viscosities (low, medium and high-viscosity). The packable composite used in the present study was a high viscosity material, and that may be the reason for the different results obtained with the low-viscosity packable composite in the study of Sadek et al. and Monticelli et al..$^{10,17}$ The lower bond strength of the packable composite in our study can be attributed to insufficient adaptation of the high viscosity composite around the post. SEM observation of groups restored with packable composite confirmed the low bond strength results, showing more voids and porosities in comparison with microhybrid and flowable composites (Figure 4).

The higher bond strength found for Z250 + Ælite core material compared to that for Biscore + Ælite can be explained by the high force of condensation of the packable composite that applies stresses to the interface, and causes a reduction in bond strength. SEM and stereomicroscope observations of the fractured post surfaces showed that the weakest link is the post-core interface, even in the groups with a combination of core materials; and, the failure mode is adhesive failure at the interface of the post and core materials (Figure 2).

The results of the present study and of the study of Ferrari indicate that different viscosities of the core material around post can cause a wide range of bond strength values. ${ }^{24}$ Ferrari concluded that in the case of using bonding agents on the post sur- 
face, the viscosity of the core material has no effect on bond strength; ${ }^{24}$ therefore, using bonding agents could result in different bond strength values in our study. Ferrari et al. explained that in the case of using bonding agents, a layer called the semi-interpenetrating polymer matrix (semi-IPN) is created on the surface of FRC posts; this layer increases bond strength. ${ }^{24}$ However, there are some studies in the literature that did not use bonding agents. ${ }^{9,21}$ It seems that applying bonding agents on the post surface with high-viscosity packable composites increases bond strength by formation of semi-IPN, whereas acceptable bonds may be created by other composites without the application of bonding agents. ${ }^{21}$

According to the results of the present study, no significant difference was found between the bond strengths of microhybrid and flowable composites. This study just measured the microtensile bond strength, and did not evaluate other mechanical properties of the materials. Therefore, it is probable that using microhybrid composites for core buildup provides acceptable penetration and mechanical properties. Since the low mechanical properties of flowable composites are reported in previous studies, ${ }^{25}$ we can benefit simultaneously from both the close adaptation of flowable composites and acceptable mechanical properties of microhybrid com-

\section{References}

1. Mumcu E, Erdemir U, Topcu FT. Comparison of micro pushout bond strengths of two fiber posts luted using simplified adhesive approaches. Dent Mater J. 2010 May;29(3):286-96.

2. Xible AA, de Jesus Tavarez RR, de Araujo C dos R, Conti PC, Bonachella WC. Effect of cyclic loading on fracture strength of endodontically treated teeth restored with conventional and esthetic posts. J Appl Oral Sci. 2006 Aug;14(4):297-303.

3. Hattori M, Takemoto S, Yoshinari M, Kawada E, Oda Y. Durability of fiber-post and resin core build-up systems. Dent Mater J. 2010 Mar;29(2):224-8.

4. Bateman G, Ricketts DN, Saunders WP. Fibre-based post systems: a review. Br Dent J. 2003 Jul 12;195(1):43-8.

5. Schwartz RS, Robbins JW. Post placement and restoration of endodontically treated teeth: a literature review. J Endod. 2004 May;30(5):289-301.

6. Fokkinga WA, Kreulen CM, Vallittu PK, Creugers NH. A structured analysis of in vitro failure loads and failure modes posites. As our experiment was performed under specific conditions, and only one type of post and few core build-up materials were used in this study, there are some limitations on the results obtained. We suggest that further investigations by different FRC posts and core materials be performed to obtain more comprehensive information in this field. It is also proposed that the study be designed and performed in fatigue conditions to provide a more dynamic and realistic environment. Clinical trials would also be of great benefit.

\section{Conclusions}

Within the limits of this study, it can be concluded that:

1. Microhybrid and flowable composites provide more acceptable bond strength in comparison to the packable materials.

2. The combination of two composites as core build-up has no effect on bond strength between the FRC post and the composite core.

\section{Acknowledgements}

The authors would like to thank the Dental Research Center and Vice Chancellor of Research, Hamadan University of Medical Sciences, for supporting this study.

of fiber, metal, and ceramic post-and-core systems. Int J Prosthodont. 2004 Jul-Aug;17(4):476-82.

7. Salameh Z, Papacchini F, Ounsi HF, Goracci C, Tashkandi E, Ferrari M. Adhesion between prefabricated fiber-reinforced posts and different composite resin cores: a microtensile bond strength evaluation. J Adhes Dent. 2006 Apr;8(2):113-7.

8. Quintas AF, Bottino MA, Neisser MP, de Araújo MA. Effect of the surface treatment of plain carbon fiber posts on the retention of the composite core: an in vitro evaluation. Pesqui Odontol Bras. 2001 Jan-Mar;15(1):64-9.

9. Goracci C, Raffaelli O, Monticelli F, Balleri B, Bertelli E, Ferrari $\mathrm{M}$. The adhesion between prefabricated FRC posts and composite resin cores: microtensile bond strength with and without post-silanization. Dent Mater. 2005 May;21(5):43744.

10. Sadek FT, Monticelli F, Goracci C, Tay FR, Cardoso PE, Ferrari M. Bond strength performance of different resin com- 
posites used as core materials around fiber posts. Dent Mater. 2007 Jan;23(1):95-9.

11. Radovic I, Monticelli F, Goracci C, Cury AH, Coniglio I, Vulicevic ZR, et al. The effect of sandblasting on adhesion of a dual-cured resin composite to methacrylic fiber posts: microtensile bond strength and SEM evaluation. J Dent. 2007 Jun;35(6):496-502.

12. Tezvergil A, Lassila LV, Vallittu PK. Strength of adhesivebonded fiber-reinforced composites to enamel and dentin substrates. J Adhes Dent. 2003 Winter;5(4):301-11.

13. Isidor F, Odman P, Brøndum K. Intermittent loading of teeth restored using prefabricated carbon fiber posts. Int J Prosthodont. 1996 Mar-Apr;9(2):131-6.

14. Pilo R, Cardash HS, Levin E, Assif D. Effect of core stiffness on the in vitro fracture of crowned, endodontically treated teeth. J Prosthet Dent. 2002 Sep;88(3):302-6.

15. Vano M, Goracci C, Monticelly F, Tognini F, Gabriele M, Tay FR, et al. The adhesion between fibre posts and composite resin cores: the evaluation of microtensile bond strength following various surface chemical treatments to posts. Int Endod J. 2006;39(1):31-9.

16. Yenisey M, Kulunk S. Effects of chemical surface treatments of quartz and glass fiber posts on the retention of a composite resin. J Prosthet Dent. 2008 Jan;99(1):38-45.

17. Monticelli F, Toledano M, Tay FR, Cury AH, Goracci C, Ferrari M. Post-surface conditioning improves interfacial adhesion in post/core restorations. Dent Mater. 2006 Jul; 22(7):602-9.
18. Pashley DH, Carvalho RM, Sano H, Nakajima M, Yoshiyama M, Shono Y, et al. The microtensile bond test: a review. J Adhes Dent. 1999 Winter;1(4):299-309.

19. Sudsangiam S, van Noort R. Do dentin bond strength tests serve a useful purpose? J Adhes Dent. 1999 Spring;1(1):57-67.

20. Labella R, Lambrechts P, Van Meerbeek B, Vanherle G. Polymerization shrinkage and elasticity of flowable composites and filled adhesives. Dent Mater. 1999 Mar;15(2):128-37.

21. Monticelli F, Goracci C, Grandini S, García-Godoy F, Ferrari M. Scanning electron microscopic evaluation of fiber postresin core units built up with different resin composites. Am J Dent. 2005 Feb;18(1):61-5.

22. Monticelli F, Goracci C, Ferrari M. Micromorphology of the fiber post-resin core unit: a scanning electron microscopy evaluation. Dent Mater. 2004 Feb;20(2):176-83.

23. Stober T, Rammelsberg P. The failure rate of adhesively retained composite core build-ups in comparison with metaladded glass ionomer core build-ups. J Dent. 2005 Jan;33(1):2732.

24. Ferrari M, Goracci C, Sadek FT, Monticelli F, Tay FR. An investigation of the interfacial strengths of methacrylate resin-based glass fiber post-core buildups. J Adhes Dent. 2006 Aug;8(4):239-45.

25. Drummond JL. Degradation, fatigue, and failure of resin dental composite materials. J Dent Res. 2008 Aug;87(8):710-9. 